\title{
Evidence for opioid modulation and generation of prostaglandins in sulphur dioxide $(\mathrm{SO})_{2}$-induced bronchoconstriction
}

\author{
Penelope I Field, Rein Simmul, Scott C Bell, David H Allen, Norbert Berend
}

\begin{abstract}
Background - Inhalation of sulphur dioxide $\left(\mathrm{SO}_{2}\right)$ provokes bronchoconstriction in asthmatic subjects. Cholinergic mechanisms contribute, but other mechanisms remain undefined. The effect of morphine, an opioid agonist, on the cholinergic component of $\mathrm{SO}_{2}$-induced bronchoconstriction was investigated, and the effect of indomethacin, a cyclooxygenase inhibitor, on $\mathrm{SO}_{2}$-induced bronchoconstriction and tachyphylaxis was studied.
\end{abstract}

Methods - In the first study 16 asthmatic subjects inhaled either ipratropium bromide or placebo 60 minutes before an $\mathrm{SO}_{2}$ challenge on days 1 and 2 . On day 3 an $\mathrm{SO}_{2}$ challenge was performed immediately after intravenous morphine. In the second study 15 asthmatic subjects took either placebo or indomethacin for three days before each study day when two $\mathrm{SO}_{2}$ challenges were performed 30 minutes apart. The response was measured as the cumulative dose causing a $35 \%$ fall in specific airways conductance (sGaw; PDsGaw ${ }_{35}$ ).

Results - Ipratropium bromide significantly inhibited $\mathrm{SO}_{2}$ responsiveness, reducing $\mathrm{PDsGaw}_{35}$ by 0.89 (95\% CI 0.46 to $1 \cdot 31)$ doubling doses. This effect persisted after correction for bronchodilatation induced by ipratropium bromide. The effect of ipratropium bromide and morphine on $\mathrm{SO}_{2}$ responsiveness also correlated $\left(r^{2}=\right.$ $0.71)$. In the second study $\mathrm{SO}_{2}$ tachyphylaxis developed with $\mathrm{PDsGaw}_{35}$ on repeated testing, being reduced by $0.62(95 \%$ CI 0.17 to 1.07 ) doubling doses. Indomethacin attenuated baseline $\mathrm{SO}_{2}$ responsiveness, increasing PDsGaw ${ }_{35}$ by 0.5 (95\% CI 0.06 to 0.93 ) doubling doses.

Conclusions - These results suggest that opioids modulate the cholinergic component of $\mathrm{SO}_{2}$ responsiveness and that cyclooxygenase products contribute to the immediate response to $\mathrm{SO}_{2}$.

(Thorax 1996;51:159-163)

Keywords: sulphur dioxide, bronchoconstriction, asthma, mechanisms.

$S$ C Bell

$\mathrm{D} \mathrm{H}$ Allen

$\mathrm{N}$ Berend

Correspondence to: Dr P I Field.

Received 5 January 1995 Returned to author 1 May 1995

Revised version received 30 August 1995

Accepted for publication 29 September 1995

In asthmatic subjects inhalation of sulphur dioxide $\left(\mathrm{SO}_{2}\right)$, a common air pollutant, causes bronchoconstriction. ${ }^{1}$ The mechanisms involved in this airway response are not clear, but it appears that activation of cholinergic nerves occurs. ${ }^{23}$ Parasympathetic nerves are the predominant bronchoconstriction neural pathway in the airways. ${ }^{4}$ It has recently been shown that opioids modulate cholinergic neurotransmission in canine airways ${ }^{5}$ and in isolated human airway smooth muscle. ${ }^{6}$ In addition, exogenous opioids have been found to inhibit the vagally mediated component of the airway response to inhaled water in asthmatic subjects. ${ }^{7}$ Opioids could modulate the cholinergic component of the airway response to $\mathrm{SO}_{2}$. This possibility was evaluated by assessing the effect of the opioid agonist, morphine sulphate, on the airway response to $\mathrm{SO}_{2}$

Cholinergic antagonists only partially protect against $\mathrm{SO}_{2}$-induced bronchoconstriction, ${ }^{238}$ indicating that other mechanisms must play a part in the response of the airways to $\mathrm{SO}_{2}$ It is now clear that many acute challenges to the airways of asthmatic subjects involve the release of mediators including cyclooxygenase products. ${ }^{910}$ Bronchoconstriction induced by inhalation of sodium metabisulphite, a sulphite preservative which is thought to act via liberated $\mathrm{SO}_{2}$, involves endogenous prostaglandins. ${ }^{11}$ We assessed the role of prostanoids in $\mathrm{SO}_{2}$-induced bronchoconstriction and tachyphylaxis by studying $\mathrm{SO}_{2}$ responsiveness after administration of indomethacin, a cyclooxygenase inhibitor.

\section{Methods}

SUBJECTS

Thirty one subjects with mild asthma gave their informed consent to take part in these studies which were approved by the Royal North Shore Hospital ethics committee. All had a prechallenge forced expiratory volume in one second $\left(\mathrm{FEV}_{1}\right)$ of at least $70 \%$ of their predicted value, no subject had had a respiratory tract infection for six weeks before testing, all were non-smokers, and all had previously demonstrated bronchial hyperresponsiveness to $\mathrm{SO}_{2}$. Inhaled sympathomimetics were withheld for six hours or more before testing, but during testing all other inhaled therapy was maintained at a constant rate.

STUDY PROTOCOLS

Opioid study completed within four weeks. All tests were performed at the same time of day (12.00 to 16.00 hours), but any two consecutive tests were separated by at least 48 hours. 
At visits 1 and 2 an $\mathrm{SO}_{2}$ challenge was performed 60 minutes after randomised, double blind administration of either nebulised $0.025 \%(500 \mu \mathrm{g})$ ipratropium bromide solution or its placebo (Boehringer Ingelheim, Germany). Two $\mathrm{ml}$ of either solution was mixed with $2 \mathrm{ml}$ of $0.9 \%$ normal saline and inhaled from an Acorn jet nebuliser attached to a Miser22 Misthaler, driven with oxygen at $81 / \mathrm{min}$. At visit 3 morphine sulphate (Sigma Pharmaceuticals Pty Ltd) was slowly injected intravenously over 15 minutes before an $\mathrm{SO}_{2}$ challenge. At the end of the challenge, $0.4 \mathrm{mg}$ of intravenous naloxone was given. Blood pressure and pulse rate were monitored before and during administration of each agent.

\section{Indomethacin study}

Fifteen subjects were studied at the same time of day on two separate days which were seven days apart. On each day, after measurement of baseline specific airways conductance (sGaw), two $\mathrm{SO}_{2}$ challenges separated by 30 minutes were performed. The second $\mathrm{SO}_{2}$ challenge was only performed if $\mathrm{sGaw}$ had returned to within $0.5 \mathrm{~s}^{-1} \mathrm{~cm} \mathrm{H} \mathrm{H}_{2} \mathrm{O}^{-1}$ of the baseline value measured before the first $\mathrm{SO}_{2}$ challenge. Subjects were pretreated with either $50 \mathrm{mg}$ oral indomethacin (Alphapharm, Australia) or placebo, taken twice daily for three days, with the final dose being taken within three hours of the first $\mathrm{SO}_{2}$ challenge. Treatments were administered in a double blind randomised fashion.

In both studies sGaw was measured before and after administration of an agent, and then immediately before an $\mathrm{SO}_{2}$ challenge.

\section{$\mathrm{SO}_{2}$ INHALATION CHALLENGE}

Thoracic gas volume and airways resistance were measured in a variable pressure, constant volume body plethysmograph (PK Morgan, UK) and converted to sGaw. ${ }^{12}$ The mean of five recordings, measured at 30 second intervals, was used on each occasion.

Subjects were challenged with $\mathrm{SO}_{2}$ during sequential three minute periods of eucapnic hyperpnoea which were separated by five minutes. After inhalation of the control partially humidified air, subjects inhaled doubling concentrations $(0 \cdot 5,1 \cdot 0,2 \cdot 0,4 \cdot 0$ and $8 \cdot 0 \mathrm{ppm})$ of $\mathrm{SO}_{2}$. A challenge was stopped when sGaw decreased by more than $60 \%$ of the control response, or the highest concentration was inhaled.

One hundred percent $\mathrm{SO}_{2}$ was delivered via a Nupro dual double pattern metering valve and $60 \mu \mathrm{m}$ filter to a stainless steel chamber where it was continually mixed with partially humidified air and fed into a 100 litre Seran bag (Aspec, Ann Arbor, Michigan, USA). End tidal carbon dioxide tension was maintained at normal resting levels during periods of hyperpnoea by adding $4-5 \% \mathrm{CO}_{2}$ to the bag gas mixture. Subjects inhaled the gas mixture using a noseclip via a two way Hans Rudolf valve. The air temperature and humidity of the inspired gas mixture, which were maintained at
$65 \%$ relative humidity and $27^{\circ} \mathrm{C}$, were measured using a Novasina temperature and humidity probe (Novasina, Switzerland) with the probe placed in the inspiratory port of the Hans Rudolf valve. Inspired $\mathrm{SO}_{2}$ concentration was continuously measured using an electrochemical cell $\mathrm{SO}_{2}$ analyser (Draeger, Sweden) through a port proximal to the Hans Rudolf valve. A Fleisch No. 3 pneumotachograph and differential pressure transducer (PK Morgan, UK) measured air flow which was digitally integrated to obtain minute ventilation (VE). A constant $\dot{V E}$ was maintained by instructing the subjects to breathe in time to a metronome and to inhale a constant tidal volume, with each subject being cued by watching their respiration on a visual display unit. Subjects inhaled a constant tidal volume of either 1.0 or 1.51 , depending on their total lung capacity. Using this method, the mean VE in the indomethacin study was $37.48(0.44) 1 / \mathrm{min}$ while in the opioid study a mean VE of $34.28(0.52) 1 / \mathrm{min}$ was achieved.

\section{DATA ANALYSIS}

Log dose response curves were constructed and the cumulative dose of $\mathrm{SO}_{2}$ needed to cause a $35 \%$ fall in sGaw was calculated by linear interpolation ( $\mathrm{PDsGaw}{ }_{35}$ ). A cumulative dose of $\mathrm{SO}_{2}$ was used as $\mathrm{SO}_{2}$ acts cumulatively when administered using the protocol described in this paper. For the purposes of analysis, if sGaw fell by $60 \%$ after inhalation of the first dose of $\mathrm{SO}_{2}$, a PDs $\mathrm{Paw}_{35}$ of $0.5 \mathrm{ppm}$ was assigned; if sGaw did not change sufficiently after administration of the highest dose of $\mathrm{SO}_{2}$, then a value of $15.5 \mathrm{ppm}$ was given. PDsGaw ${ }_{35}$ values were log transformed for analysis and are expressed as geometric mean values with $95 \%$ confidence intervals. The effect of treatment on $\mathrm{SO}_{2}$ responsiveness was calculated by comparing the difference in log $\mathrm{PDsGaw}_{35}$ after active and placebo treatments and is expressed in terms of doubling doses. $\mathrm{SO}_{2} \mathrm{PDsGaw}_{35}$ and the difference in $\mathrm{PDsGaw}_{35}$ for $\mathrm{SO}_{2}$ challenges were compared within subjects by the paired $t$ test. Regression analysis was used to examine the relationship between the effect of ipratropium bromide and morphine on $\mathrm{SO}_{2}$ and to relate the change in sGaw after ipratropium bromide to the change in PDsGaw $\mathrm{P}_{35}$ after ipratropium bromide. Airway conductance measurements are expressed as means (SD). Analysis of variance was used to assess if there were any differences in sGaw before and after treatments. A p value of $<0.05$ was considered significant.

Table 1 Mean (SD) airway calibre measured as specific airways conductance (s $\mathrm{Gaw} ; \mathrm{s}^{-1} \mathrm{~cm} \mathrm{H}_{2} \mathrm{O}^{-1}$ ) before and after treament with placebo, ipratropium bromide (IPB), and morphine

\begin{tabular}{lll}
\hline Agent & Before agent & After agent \\
\hline Placebo & $0 \cdot 18(0.09)$ & $0 \cdot 19(0.08)$ \\
IPB & $0 \cdot 19(0 \cdot 11)$ & $0.26(0.07)^{*}$ \\
Morphine & $0.19(0 \cdot 10)$ & $0.18(0.08)$
\end{tabular}

${ }^{*} \mathrm{p}<0.05$ compared with value before IPB 


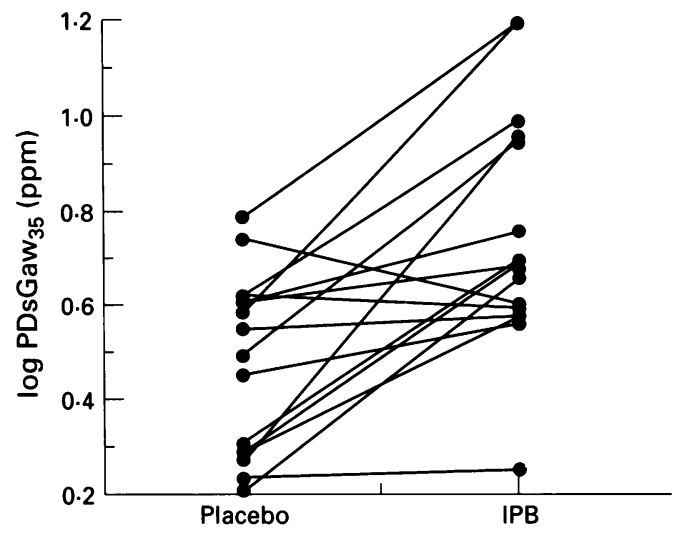

Figure 1 Individual doses of sulphur dioxide $\left(\mathrm{SO}_{2}\right)$ causing a $35 \%$ fall in specific airways conductance $\left(P D s G a w_{35}\right.$ ) after placebo and after ipratropium bromide (IPB) in 16 mild asthmatic subjects.

\section{Results}

OPIOID STUDY

Sixteen asthmatic subjects (10 men) aged 25-50 years with a mean prechallenge $\mathrm{FEV}_{1}$ of $87(4.6) \%$ (range $70-111 \%$ ) were recruited. Five subjects were taking inhaled steroids regularly (beclomethasone dipropionate,

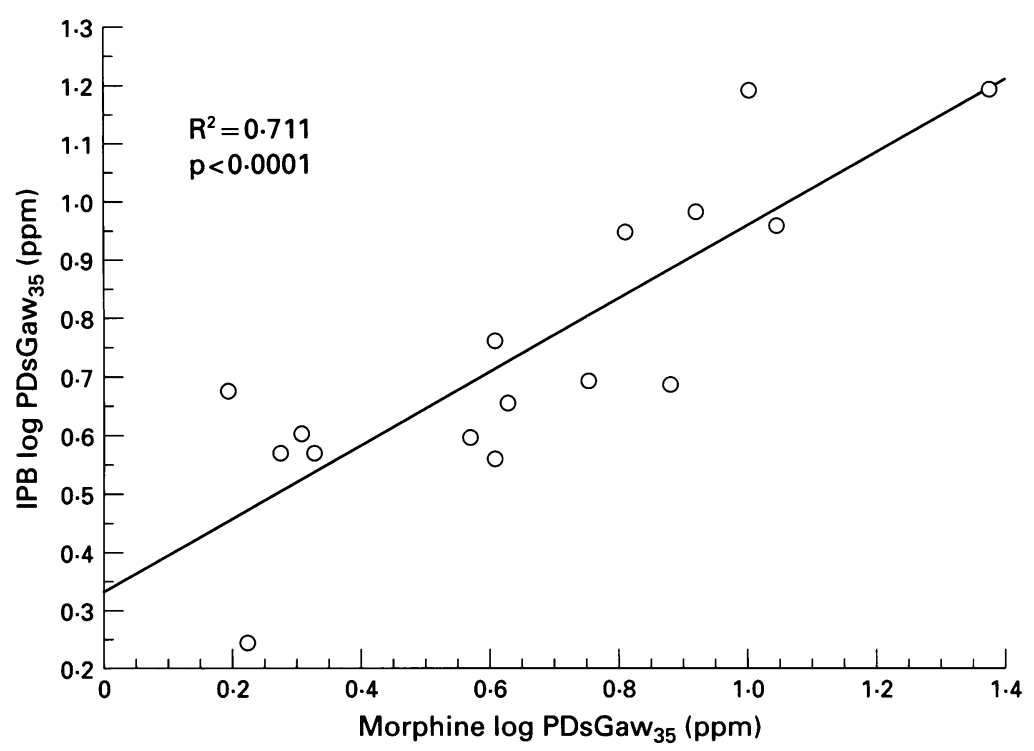

Figure 2 Comparison of the effect of ipratropium bromide (IPB) and the effect of morphine on airway responsiveness to sulphur dioxide $\left(\mathrm{SO}_{2}\right)$ in 16 mild asthmatic subjects.

Table 2 Doses of sulphur dioxide $\left(\mathrm{SO}_{2}\right)$ provoking a 35\% fall in specific airways conductance (PDsGaw ${ }_{35}$ ) in ppm for $\mathrm{SO}_{2}$ challenges on placebo and indomethacin study days

\begin{tabular}{|c|c|c|c|c|}
\hline \multirow[t]{2}{*}{ Subject no. } & \multicolumn{2}{|c|}{ Placebo study day } & \multicolumn{2}{|c|}{ Indomethacin study day } \\
\hline & First challenge & Second challenge & First challenge & Second challenge \\
\hline 1 & 0.50 & $2 \cdot 40$ & $1 \cdot 70$ & 1.65 \\
\hline 2 & 0.80 & 3.00 & 1.70 & 1.55 \\
\hline 3 & $1 \cdot 25$ & 3.65 & $3 \cdot 50$ & $4 \cdot 00$ \\
\hline 4 & 1.05 & 2.05 & $3 \cdot 70$ & $4 \cdot 60$ \\
\hline 5 & $4 \cdot 50$ & $8 \cdot 90$ & $5 \cdot 20$ & $5 \cdot 40$ \\
\hline 6 & $9 \cdot 80$ & $11 \cdot 75$ & $10 \cdot 80$ & $10 \cdot 80$ \\
\hline 7 & $3 \cdot 55$ & $5 \cdot 60$ & $3 \cdot 70$ & $3 \cdot 50$ \\
\hline 8 & $3 \cdot 90$ & $5 \cdot 90$ & $6 \cdot 60$ & $6 \cdot 00$ \\
\hline 9 & $4 \cdot 80$ & $7 \cdot 90$ & $8 \cdot 20$ & $15 \cdot 50$ \\
\hline 10 & $1 \cdot 80$ & $2 \cdot 30$ & $2 \cdot 25$ & $3 \cdot 80$ \\
\hline 11 & $4 \cdot 75$ & 4.05 & $4 \cdot 35$ & $5 \cdot 00$ \\
\hline 12 & $2 \cdot 80$ & $2 \cdot 75$ & $4 \cdot 00$ & $2 \cdot 50$ \\
\hline 13 & $7 \cdot 80$ & $7 \cdot 00$ & $4 \cdot 45$ & $4 \cdot 20$ \\
\hline 14 & $5 \cdot 80$ & $5 \cdot 60$ & $4 \cdot 80$ & $3 \cdot 90$ \\
\hline & $5 \cdot 50$ & 3.90 & $4 \cdot 40$ & $3 \cdot 70$ \\
\hline Geometric mean & $2 \cdot 91$ & $4 \cdot 48$ & $4 \cdot 10$ & $4 \cdot 22$ \\
\hline SD & $2 \cdot 42$ & 1.71 & 1.67 & 1.82 \\
\hline
\end{tabular}

$400-1000 \mu \mathrm{g} /$ day) and all took an inhaled $\beta_{2}$ agonist as required. No subject developed bronchoconstriction after inhaling the control partially humidified air for three minutes.

The baseline sGaw was similar in each study (table 1) and did not change significantly after administration of placebo and morphine, but after iprat-opium bromide there was a significant increase in sGaw $(p<0 \cdot 05)$. However, the degree of bronchodilatation induced by ipratropium bromide and the effect of ipratropium bromide on $\mathrm{SO}_{2}$ airways responsiveness $\left(R^{2}=0 \cdot 29\right)$ were not significantly correlated.

Ipratropium bromide attenuated $\mathrm{SO}_{2}$ responsiveness. The placebo geometric mean $\mathrm{PDsGaw}_{35}$ of $2.97 \mathrm{ppm}$ increased to $5.50 \mathrm{ppm}$ after ipratropium bromide, a mean difference of 0.89 (95\% CI 0.46 to 1.31 ) doubling doses $(p<0.0005)$ (fig 1). The effects of ipratropium bromide and morphine on $\mathrm{SO}_{2} \mathrm{PDsGaw}_{35}$ were significantly correlated $\left(R^{2}=0.71, \mathrm{p}<0.0001\right)$ (fig 2).

\section{INDOMETHACIN STUDY}

This study involved six men and nine women with asthma aged 19-60 years with a mean prechallenge $\mathrm{FEV}_{1}$ of $92 \cdot 3$ (3.2)\% (range 73$124 \%$ ). All subjects were receiving treatment with inhaled $\beta$ agonists only. No subject developed bronchoconstriction after inhaling the control partially humidified air for three minutes.

Baseline airway calibre before $\mathrm{SO}_{2}$ challenges on the placebo and indomethacin study days did not differ significantly. On the placebo day the mean sGaw before the first and second $\mathrm{SO}_{2}$ challenges were $0.14(0.02)$ and $0.14(0.16)$ $\mathrm{s}^{-1} \mathrm{~cm} \mathrm{H}_{2} \mathrm{O}^{-1}$, respectively. On the indomethacin day the mean sGaw before the first and second $\mathrm{SO}_{2}$ challenges were both $0 \cdot 14$ $(0 \cdot 02) \mathrm{s}^{-1} \mathrm{~cm} \mathrm{H}_{2} \mathrm{O}^{-1}$.

$\mathrm{SO}_{2}$ tachyphylaxis was measured after administration of placebo (table 2). On the placebo day the first and second challenge geometric mean $\mathrm{PDsGaw}_{35}$ values were $2.91 \mathrm{ppm}$ and $4.48 \mathrm{ppm}$, a mean difference of $0.62(95 \%$ CI 0.17 to 1.07$)$ doubling doses $(p<0 \cdot 01)$. Indomethacin significantly attenuated baseline $\mathrm{SO}_{2}$ responsiveness. On the indomethacin day the first challenge geometric mean $\mathrm{PDsGaw}_{35}$ of $4 \cdot 10 \mathrm{ppm}$ differed significantly $(p<0.05)$ from the placebo first challenge geometric mean of $2.91 \mathrm{ppm}$, the mean difference being 0.50 (95\% CI 0.06 to 0.93 ) doubling doses. After indomethacin there was no significant difference between the first and second challenge geometric mean PDsGaw 35 values of 4.10 and $4.22 \mathrm{ppm}$, respectively. There was also no significant difference between the placebo and indomethacin second challenge geometric mean PDsGaw 35 values of 4.48 and $4.22 \mathrm{ppm}$.

\section{Discussion}

We have reported mechanisms which could contribute to the response of the airways to $\mathrm{SO}_{2}$ in subjects with asthma. Firstly, it has been 
shown that the cholinergic component of $\mathrm{SO}_{2}-$ induced bronchoconstriction can be modulated by exogenous opioids and, secondly, that cyclooxygenase products mediate the immediate bronchoconstrictive response to $\mathrm{SO}_{2}$. The attenuation of $\mathrm{SO}_{2}$-induced bronchoconstriction by ipratropium bromide is consistent with results from previous studies ${ }^{238}$ in which muscarinic receptor antagonists have partially inhibited the response of the airways to $\mathrm{SO}_{2}$. Ipratropium bromide provided a variable protection against inhaled $\mathrm{SO}_{2}$. Similar variability has been observed in other studies, ${ }^{238}$ with clearcut inhibition being demonstrated in one study ${ }^{2}$ and more variable protection in others. ${ }^{38}$ The bronchodilatation induced by ipratropium bromide could contribute to its variable protective effect. However, in our study there was no relationship between the degree of protection afforded by ipratropium bromide and the degree of bronchodilatation.

The similar degree of inhibition of the airways response to $\mathrm{SO}_{2}$ by ipratropium bromide and morphine suggests that opioids modulate the cholinergically mediated component of the bronchoconstrictive response to $\mathrm{SO}_{2}$. There is to our knowledge only one other published study demonstrating opioid inhibition of cholinergically mediated bronchoconstriction in humans in vivo. ${ }^{7}$ In that study morphine inhibited the vagally mediated component of water-induced bronchoconstriction via opioid receptors in subjects with asthma. Opioid receptors have been identified throughout the central and peripheral nervous system ${ }^{13}$ and are present in lung tissue. ${ }^{14}$ The site at which morphine acts to modulate $\mathrm{SO}_{2}$-induced bronchoconstriction is not known, but opioid receptors have been localised to sensory fibres of the vagus nerves. ${ }^{15}$ In in vitro studies of human ${ }^{6}$ and canine ${ }^{5}$ airways it has been shown that exogenous opioids modulate cholinergic neurotransmission by stimulating prejunctional postganglionic $\mu$ opioid receptors which inhibit acetylcholine release. ${ }^{6}$ In some animal models, however, cholinergic neurotransmission is enhanced by tachykinins and opioids reduce cholinergic neurotransmission by inhibiting the release of tachykinins from airway sensory nerves. ${ }^{16}$ Tachykinins now appear to be involved in the airway responses to inhaled metabisulphite, ${ }^{17}$ a sulphite preservative which is thought to act via liberated $\mathrm{SO}_{2}$ Thus, opioids could modulate the vagally mediated component of $\mathrm{SO}_{2}$-induced bronchoconstriction by inhibiting the action of endogenously released tachykinins. However, non-cholinergic neural constrictor responses have not been found in in vitro studies of human airways, ${ }^{6}$ and tachykinins do not appear to modulate cholinergic neurotransmission. ${ }^{18}$

The attenuation of initial $\mathrm{SO}_{2}$ responsiveness by indomethacin suggests that the airway response to $\mathrm{SO}_{2}$ is partially mediated by cyclooxygenase products present in the airways of asthmatic subjects. However, this effect of indomethacin on initial $\mathrm{SO}_{2}$ responsiveness confounded interpretation of the effect of indomethacin on the development of $\mathrm{SO}_{2}$ tachyphylaxis. After indomethacin the mean change in $\mathrm{SO}_{2}$ responsiveness between the first and second challenge was significantly less than after placebo. This difference may have been due solely to the change in initial $\mathrm{SO}_{2}$ responsiveness induced by indomethacin, but it may also have reflected an inhibition of the development of $\mathrm{SO}_{2}$ tachyphylaxis by indomethacin.

The effect of indomethacin in attenuating airways responsiveness to $\mathrm{SO}_{2}$ was small, indicating that cyclooxygenase products are likely to play a minor role. The dose of indomethacin administered should have provided adequate inhibition of prostanoid production, as similar doses have been effective in inhibiting allergeninduced bronchoconstriction ${ }^{9}$ and in attenuating histamine tachyphylaxis ${ }^{10}$ in asthmatic subjects. At the dose used in this study the production of prostaglandins is suppressed on average by more than $70 \%,{ }^{19}$ but between subjects there is considerable variation in plasma levels following a given dose. ${ }^{19}$ It is therefore possible that, with the use of a different cyclooxygenase inhibitor, greater inhibition of $\mathrm{SO}_{2}$-induced bronchoconstriction may have occurred. When different cyclooxygenase inhibitors have been used to study the role of prostanoids in bronchoconstriction induced by inhalation of sodium metabisulphite, disparate results have been obtained. Flurbiprofen caused significant attenuation of the constrictor response to sodium metabisulphite, ${ }^{11}$ while indomethacin had no effect. ${ }^{20}$

The results of our study have confirmed that asthmatic subjects can develop tachyphylaxis to $\mathrm{SO}_{2}{ }^{21}$ The underlying mechanisms are not known. A loss of airway smooth muscle responsiveness to released neurotransmitters does not appear to be involved as the bronchoconstrictor response to histamine, a direct airway smooth muscle agonist, is preserved after development of $\mathrm{SO}_{2}$ tachyphylaxis. ${ }^{21}$ Inhibitory prostaglandins may play a part as refractoriness to the bronchoconstrictor response to sodium metabisulphite has been shown to involve inhibitory prostaglandins. ${ }^{20}$ Unfortunately, it was not possible in our study to determine whether inhibitory cyclooxygenase products also contributed to the development of $\mathrm{SO}_{2}$ tachyphylaxis.

The source of cyclooxygenase products that contribute to the bronchoconstrictive response to $\mathrm{SO}_{2}$ remains undetermined. Prostaglandins with bronchoconstrictor properties such as $\mathrm{PGD}_{2}$ are generated by mast cells. ${ }^{22}$ However, the role of mast cells in $\mathrm{SO}_{2}$ airway responsiveness is unclear. Sodium cromoglycate which blocks the release of mast cell mediators such as histamine inhibits the airway response to $\mathrm{SO}_{2}{ }^{8}$ but the antihistamine terfenadine $e^{23}$ does not affect airway responsiveness to sulphites. Another source of bronchoconstricting prostaglandins is airway epithelium. ${ }^{24}$ One mechanism by which $\mathrm{SO}_{2}$ could stimulate generation of epithelial-derived prostaglandins is via bradykinin. In allergic sheep inhalation of metabisulphite solutions promotes the release of lung kinins ${ }^{25}$ which could stimulate the generation of prostaglandins via specific receptors present on airway epithelial cells. ${ }^{24}$ 
In conclusion, the airway response to $\mathrm{SO}_{2}$ involves the release of inflammatory mediators. In addition, the parasympathetic reflexes which play a part in the $\mathrm{SO}_{2}$-induced bronchoconstriction have the potential to be modulated by opioids.

The authors acknowledge the support of The Asthma Foundation of New South Wales.

1 Stevenson DD, Simon RA. Sensitivity to ingested metabisulfites in asthmatic subjects. F Allergy Clin Immunol 1981;68:26-32.

2 Tan WC, Cripps E, Douglas N, Sudlow MF. Protective effect of drugs on bronchoconstriction induced by sulphur effect of drugs on bronchoconstrictic
dioxide. Thorax 1982;37:671-6.

3 Sheppard D, Scott-Wong W, Vehara CF, Nadel JA, Boushey HA. Lower threshold and greater bronchomotor responsiveness of asthmatic subjects to sulfur dioxide. Am Rev Respir Dis 1981;122:873-8.

4 Barnes PJ. Neural control of human airways in health and disease. Am Rev Respir Dis 1986;134:1289-314.

5 Russell JA, Simons EJ. Modulation of cholinergic neurotransmission in airways by enkephalin. $\mathcal{F} A$ ppl Physiol 1985 58:853-8.

6 Belvisi MG, Stretton CD, Verleden GM, Ledingham SJL, Yacoub MH, Barnes PJ. Inhibition of cholinergic neurotransmission in human airways by opioids. $\mathcal{F}$ Appl Physiol 1992;72:1096-100.

7 Eschenbacher WL, Bethel RA, Boushey HA, Sheppard D. Morphine sulfate inhibits bronchoconstriction in subjects with mild asthma whose responses are inhibited by atropine. Am Rev Respir Dis 1984;130:363-7.

8 Myers DJ, Bigby BG, Calvayrac P, Sheppard D, Boushey $\mathrm{HA}$. Interaction of cromolyn and a muscarinic antagonis in inhibiting bronchial reactivity to sulphur dioxide and to eucapnic hyperpnea alone. Am Rev Respir Dis 1986; 133:1154-8.

9 Sladek K, Dworski R, Fitzgerald GA, Buitkus KL, Block FJ, Marney SR, et al. Allergen-stimulated release of thromboxane $A_{2}$ and leukotriene $E_{4}$ in humans. Effect of indomethacin. Am Rev Respir Dis 1990;141:1441-5.

10 Manning PJ, Jones GL, O'Byrne PM. Tachyphylaxis to inhaled histamine in asthmatic subjects. $₹$ Appl Physiol inhaled histamine

11 O'Connor BJ, Barnes PJ, Chung KF. Inhibition of sodium metabisulphite induced bronchoconstriction by frusemide in asthma: role of cyclooxygenase products. Thorax 1994; 49:307-11.

12 Dubois AB, Botelho SY, Comroe JH. A new method for measuring airway resistance in man using a body plethysmograph: values in normal subjects and in patients with respiratory disease. 7 Clin Invest 1956;35:327-35.

13 Lord JAH, Waterfield AA, Hughes J. Endogenous opioid peptides: multiple agonists and receptors. Nature 1977; peptides: mult

14 Tang J, Chou J, Zhang AZ, Yang H-YT, Costa E. Met5encephalin-arg6-phe7 and its receptor in lung. Life $S c$ 1983,32:2371-7.

15 Atweh SF, Murrin LC, Kuhar MJ. Presynaptic localization of opiate receptors in the vagal and accessory optic systems: an autoradiographic study. Neuropharmacology 1978;17 65-71.

16 Belvisi MG, Streeton CD, Barnes PJ. Modulation of cholinergic neurotransmission in guinea-pig airways by opioids. Br F Pharmacol 1990;100:131-7.

17 Bellofiore S, Caltagirone F, Pennisi A, Ciancio N, Mistretta A, Di Maria GU. Neutral endopeptidase inhibitor thiorphan increases airway narrowing to inhaled sodium metabisulfite in normal subjects. Am 7 Respir Crit Care $M e d$ 1994;150:853-6.

18 Black JL, Johnson PR, Alouvan L, Armour CL. Neurokinin A with $\mathrm{K}+$ channel blockade potentiates contraction to electrical stimulation in human bronchus. Eur $¥$ Pharmacol 1990;180:311-7.

19 Rane A, Oelz O, Frolich JC, Seyberth HW, Sweetman BJ, Watson JT, et al. Relation between plasma concentration of indomethacin and its effect on prostaglandin synthesis and platelet aggregation in man. Clin Pharmacol Ther 1978 23:658-68.

20 Pavord ID, Wisniewski A, Tattersfield AE. Refractoriness to inhaled sodium metabisulphite in subjects with mild asthma. Eur Respir f 1994;7:50-4.

21 Sheppard D, Epstein J, Bethel RA, Nadel JA, Boushey HA Tolerance to sulfur dioxide-induced bronchoconstriction in subjects with asthma. Envirn Res 1983;30:412-9.

22 Holtzman MJ. Arachidonic acid metabolism. Implication of biological chemistry for lung function and disease. $A m$ Rev Respir Dis 1991:143:188-203.

23 Dixon CMS, Ind PW. Metabisulphite-induced bronchoconstriction: mechanisms. Am Rev Respir Dis 1988;137: A238.

24 Churchill L, Chilton FH, Resau JH, Bascom R, Hubbard WC, Proud D. Cyclooxygenase metabolism of endogenous arachidonic acid by cultured human tracheal epithelial arachidonic acid by cultured human tracheal
cells. $A m$ Rev Respir $D$ is $1989 ; 140: 449-59$.

25 Mansour E, Ahmed A, Cortes A, Caplan J, Burch RM Abraham WM. Mechanisms of metabisulfite-induced stimulation. $\mathcal{F}$ Appl Physiol 1992;72:1831-7. 